\title{
Apoptotic effects of extract from Cnidium monnieri (L.) Cusson by adenosine monosphosphate-activated protein kinase-independent pathway in HCT116 colon cancer cells
}

\author{
EUN GYEONG LIM ${ }^{1}$, GUEN TAE KIM ${ }^{1}$, SE HEE LEE ${ }^{1}$, SANG-YONG KIM ${ }^{2}$ and YOUNG MIN KIM ${ }^{1}$ \\ ${ }^{1}$ Department of Biological Sciences and Biotechnology, College of Life Science and Nanotechnology, Hannam University, \\ Yuseong-Gu, Daejeon 305-811; ${ }^{2}$ Biongene, Chongro-GU, Seoul 110-521, Republic of Korea
}

Received November 18, 2014; Accepted December 15, 2015

DOI: $10.3892 / \mathrm{mmr} .2016 .5115$

\begin{abstract}
Colon cancer, a common malignancy, can occur due to poor eating habits and increasing age. Consequently, careful regulation of eating habits may serve as a possible method for preventing the occurrence or progression of colon cancer. Extracts of the fruit of Cnidium monnieri (L.) Cusson are well-known as an effective herbal medicine for the treatment of pain in female genitalia and carbuncle. However, there have been no studies on the apoptotic effects of Cnidiummonnieri (L.) Cusson (CME). Adenosine monophosphate-activated protein kinase (AMPK), the major regulator of energy metabolism, is activated by metabolic stress, including hypoxia and glucose deprivation. Activation of AMPK inhibits cell proliferation and induces apoptosis through the inhibition of phosphorylated (p)-Akt and control of B-cell lymphoma 2 (Bcl-2) family members. The pro-apoptotic proteins Bcl-2-associated $\mathrm{X}$ protein (Bax) and Bcl-2-homologous antagonist killer (Bak), are activated by their translocation to mitochondria from the cytosol. Translocation of Bax/Bak induces outer membrane permeabilization and is likely to lead to apoptosis through cytochrome $\mathrm{C}$ release and caspase activity. In the present study, the apoptotic effects and influence on mitochondria-mediated apoptotic proteins of CME in HCT116 cells were assessed. We hypothesized that CME may have an effect on the inhibition of p-Akt in an AMPK-independent pathway. The present study demonstrated that CME induced the release of LDH and apoptosis through its inhibition of p-Akt to control Bcl-2 and activate Bax and Bak. Co-treatment with CME and AMPK inhibitors showed that CME-induced apoptosis does not occurr through a AMPK-dependent pathway. Therefore, the
\end{abstract}

Correspondence to: Professor Young Min Kim, Department of Biological Sciences and Biotechnology, College of Life Science and Nanotechnology, Hannam University, 1646 Yuseong-dero, Yuseong-Gu, Daejeon 305-811, Republic of Korea

E-mail:kym@hnu.kr

Key words: adenosine monosphosphate-activated protein kinase, mitochondria proteins, apoptosis, Akt, colon cancer cells present study determined, for the first time, that CME induced apoptosis as a result of causing metabolic stresses due to directly regulation of the de-phosphorylation of Akt, whereas it did not control the AMPK-dependent pathway in HCT116 colon cancer cells.

\section{Introduction}

Colon cancer is a common malignancy with a high incidence worldwide, which is increasing each year in South Korea as the population ages and adapts to westernized eating habits (1-3). Most attention is focused on post-operative cancer metastasis, as the post-operative survival rate of colon cancer is only $50 \%$ (4). Cancer cells require large amounts of energy and molecules, including lipids and amino acids, for cell growth and proliferation and to protect themselves through the regulation of pro-survival factors (5). The number of studies on the potential use of natural plant extracts for the inhibition of cancer-cell proliferation and metastasis through the regulation of pro-survival factors has increased (4-6). A number of previous studies have shown that various active components of herbal medicines, such as curcumin, as well as selenium, induce apoptosis through the regulation of AMP-activated protein kinase (AMPK) and Akt in colon cancer cells $(4,5,7)$. The adjustment of eating habits may have beneficial effects on the AMPK and Akt pathways and prevent the occurrence or the progression of colon cancer.

Apoptosis is the programmed cell death as a response to cell damage through various biological events, including DNA damage, hypoxia, cell cycle arrest and metabolic stress (8). AMPK is activated by metabolic stress, including hypoxia, heat shock and energy deprivation. In addition, AMPK induces apoptosis through the inhibition of the mammalian target of rapamycin (mTOR) pathway, which regulates the growth and supply of nutrition to cancer cells $(5,9,10)$. Furthermore, AMPK has been demonstrated to be an upstream factor of the phosphoinositide-3 kinase (PI3K)/Akt pathway and induce the phosphorylation of forkhead box O3a (11). Akt, one of the serine/threonine protein kinases, regulates cancer growth and proliferation by phosphorylation of mTOR, and inhibits the expression of pro-apoptotic proteins, including B-cell lymophoma 2 (Bcl-2)-associated X protein (Bax) and 
Bcl-2 homologous antagonist killer (Bak), thereby suppressing apoptosis $(12,13)$.

A previous study showed that a polysaccharide extract from a medicinal mushroon induced apopotosis in colon cancer cells via the suppression of Bcl-2 and activation of Bax/Bak (14). The intrinsic apoptotic pathway, which is mitochondria-dependent, is activated by the release of apoptotic molecules into the cytosol from the mitochondria through a change in mitochondrial membrane permeability (MMP) caused by mitochondrial dysfunction $(8,15-17)$. The Bcl-2 family is well known to participate in changes of the MMP; in particular, Bcl-2 has been found to suppress apoptosis through inhibiting pro-apoptotic proteins, including Bax and $\operatorname{Bak}(8,13,18)$. The Bcl-2 family also has a major role in the mitochondria-dependent activation of caspases (19). Therefore, regulation of the pro-survival factor $\mathrm{Bcl}-2$, and its upstream regulators may represent an effective treatment for cancer.

Numerous studies have shown that Bax and Bax are major pro-apoptotic proteins in mitochondria-mediated apoptosis. Activation of Bax/Bak results in their translocation to mitochondria from the cytosol, where they oligomerize with each other (20). For this reason, pores are formed in the mitochondrial outer membrane and cytochrome $\mathrm{C}$ is released into the cytosol (21), where it activates caspase-9, which in turn forms the apoptosome complex with apoptotic protease activating factor $1(19,22)$. The apoptosome complex activates caspase-3 through the cleavage of pro-caspase-3 (22).

A large number of previous studies have detailed the apoptotic effects of various plant extracts through the regulation of AMPK and the Akt pathway in colon cancer cells $(1,4,9)$. Cnidium monnieri (L.) Cusson is an umbelliferous plant and has been used for the treatment of impotence, pain in female genitalia, suppurative dermatitis and carbuncle $(23,24)$. The fruit of Cnidium monnieri (L.) Cusson is widely used as a medicinal herb (25); however, the anti-cancer effects of Cnidium monnieri (L.) Cusson extract (CME) have not been investigated. Accordingly, the present study investigated the effects of CME on mitochondria-mediated apoptotic proteins and apoptosis in HCT116 colon cancer cells. Furthermore, AMPK and Akt inhibitors were employed to assess whether the mechanism of action of CME is dependent or independent of the associated signaling pathways.

\section{Materials and methods}

Reagent. Cnidium monnieri (L.) Cusson (CME) was purchased from Dong Kyung PHARM (Seoul, Korea). A total of $100 \mathrm{~g} \mathrm{CME}$ was soaked in $99 \%$ ethanol $(800 \mathrm{ml})$ stirred at room temperature for $48 \mathrm{~h}$. The extract was filtered through qualitative filter paper no.1 (Toyo Roshi Kaisha, Ltd., Tokyo, Japan) and concentrated with a rotary evaporator to remove the ethanol. CME was dissolved in dimethyl sulfoxide (stock solution, $120-200 \mu \mathrm{g} / \mathrm{ml}$ ) prior to treatment and stored at $-20^{\circ} \mathrm{C}$. The final concentration of CME in the culture medium was controlled at $120-200 \mu \mathrm{g} / \mathrm{ml}$. The fluorescein isothiocyanate-Annexin $\mathrm{V}$ apoptosis detection kit was obtained from BD Biosciences (Franklin Lakes, NJ, USA). The Pierce lactate dehydrogenase (LDH) Cytotoxicity Assay kit was purchased from Thermo Fisher Scientific (Waltham, MA, USA). The Caspase-3 Activity Assay kit was obtained from Abcam (Cambridge, MA, USA). Specific antibodies that recognized phosphorylated (p)mTOR (Ser2448) (2971), (p)Akt (Ser473) (4051), (p)AMPKa1 (Thr172) (2535), Bax (5023), Bak (6947), pro-caspase-3 (9665), Bcl-2 (2876) and $\beta$-actin (4967) were obtained from Cell Signaling Technology (Beverly, MA, USA) and P53-upregulated modulator of apoptosis (PUMA) antibody (4976) was purchased from Santa Cruz Biotechnology (Dallas, TX, USA). LY294002 (PI3K/Akt inhibitor) and Compound C (AMPK inhibitor) were purchased from Calbiochem (San Diego, CA, USA). Horseradish peroxidase (HRP)-conjugated goat anti-mouse (PA1-30126) and goat anti-rabbit (166-2408) secondary antibodies were purchased from Thermo Fisher Scientific, Inc., and Bio-Rad Laboratories, Inc., (Tokyo, Japan), respectively.

Cell culture. HCT116 colon cancer cells were obtained from the American Type Culture Collection (Rockville, MD, USA). The cells were grown in RPMI-1640 medium (Hyclone Laboratories Inc., Logan, UT, USA) containing 10\% fetal bovine serum (Hyclone Laboratories Inc.) and $1 \%$ antibiotics (100 mg/l streptomycin and $100 \mathrm{U} / \mathrm{ml}$ penicillin; Hyclone Laboratories Inc.) at $37^{\circ} \mathrm{C}$ in a $5 \% \mathrm{CO}_{2}$ atmosphere. The cells were sub-cultured by detachment with Trypsin-EDTA (Hyclone Laboratories Inc.) and re-seeding at $1 \times 10^{6}$ cells $/ \mathrm{ml}$ per 100-mm plate every $48 \mathrm{~h}$.

$L D H$ release assay. Cells were seeded at $2.5 \times 10^{5}$ cells $/ \mathrm{ml}$ per well in a 96-well plate and incubated for $24 \mathrm{~h}$. The cells were then treated with CME (120-200 $\mu \mathrm{g} / \mathrm{ml})$ and then incubated at $37^{\circ} \mathrm{C}$ in a $5 \% \mathrm{CO}_{2}$ atmosphere. Certain samples were pre-treated with the respective inhibitor (10 $\mu \mathrm{M}$ Compound $\mathrm{C}$ or $40 \mu \mathrm{M}$ LY294002) for $30 \mathrm{~min}$ prior to treatment with CME. After $24 \mathrm{~h}$, the high control cells (maximum LDH release) control cells were treated with Cell Lysis solution from the LDH Cytotoxicity Assay kit for 45 min followed by centrifugation at $250 \mathrm{xg}$ for $3 \mathrm{~min}$. The absorbance of the solution in each well was determined using a microplate reader (Bio-Rad Laboratories, Inc.) at 490 and $655 \mathrm{~nm}$.

Determination of apoptosis by Annexin V/propidium iodide (PI) staining. Cells were seeded at $1 \times 10^{6}$ cells $/ \mathrm{ml}$ in a $60-\mathrm{mm}$ plate and incubated for $24 \mathrm{~h}$. The cells were then treated with CME $(120-180 \mu \mathrm{g} / \mathrm{ml})$ for $24 \mathrm{~h}$ at $37^{\circ} \mathrm{C}$ in a $5 \% \mathrm{CO}_{2}$ atmosphere. Certain samples were pre-treated with the respective inhibitor (10 $\mu \mathrm{M}$ Compound $\mathrm{C}$ or $40 \mu \mathrm{M}$ LY294002) for $30 \mathrm{~min}$ prior to treatment with CME. Total cells were harvested by trypsinization, collected by centrifugation, washed with phosphate-buffered saline (PBS) and re-suspended in binding buffer. Cells were stained with Annexin V and PI for 15 min. Fluorescence intensity was analyzed using a FACS Canto flow cytometer (BD Biosciences).

Identification of apoptosis by Hoechst 33342 staining. Cells were seeded at $1 \times 10^{4}$ cells $/ \mathrm{ml}$ in a 12 -well plate containing glass cover slips (Marienfeld-Superior GmbH \& Co., Lauda-Königshofen, Germany) and incubated for $24 \mathrm{~h}$. Following incubation, the cells were treated with the $\mathrm{CME}$ $(120,140$ or $160 \mu \mathrm{g} / \mathrm{ml})$ for $24 \mathrm{~h}$ at $37^{\circ} \mathrm{C}$ in a $5 \% \mathrm{CO}_{2}$ atmosphere. The cells were then stained with $0.7 \mu \mathrm{M}$ Hoechst 33342 and incubated for $30 \mathrm{~min}$. Cells were fixed with $3.5 \%$ 
formaldehyde $(500 \mu \mathrm{l})$ for $20 \mathrm{~min}$ and then gently washed with $150 \mu \mathrm{l}$ PBS for 5 min (thrice) The slips were mounted with $10 \mu \mathrm{l}$ of mounting solution (50\% glycerol). The stained chromatin fragments indicative of apoptosis were observed using a fluorescence microscope (magnification, x200; Axioskop 50; Carl Zeiss, Inc., Thornwood, NY, USA).

Western blot analysis. Cells were seeded at $1 \times 10^{5}$ cells $/ \mathrm{ml}$ in a six-well plate and incubated for $24 \mathrm{~h}$. The cells were then treated with CME $(120,140$ or $160 \mu \mathrm{g} / \mathrm{ml})$ for $24 \mathrm{~h}$ at $37^{\circ} \mathrm{C}$ in a $5 \% \mathrm{CO}_{2}$ atmosphere. Certain samples were pre-treated with the respective inhibitor $(10 \mu \mathrm{M}$ Compound $\mathrm{C}$ or $40 \mu \mathrm{M}$ LY294002) for $30 \mathrm{~min}$ prior to treatment with CME. Cells were then rinsed twice with ice-cold PBS and scraped with radioimmunoprecipitation assay lysis buffer $(50 \mathrm{mM}$ Tris- $\mathrm{HCl} \mathrm{pH}$ 8.0, $150 \mathrm{mM} \mathrm{NaCl}, 1 \% \mathrm{NP}-40,0.5 \%$ sodium deoxycholate and $1 \mathrm{mM}$ phenylmethanesulfonylfluoride) [all purchased from Cell Signaling Technology, Inc. (Beverly, MA, USA)] and subjected to western blot analysis. Protein quantification was performed using Bradford assay and $30 \mu \mathrm{g}$ protein was loaded per lane. Nitrocellulose membranes (GE Healthcare Life Sciences, Chalfont, UK) were blocked with $2 \%$ bovine serum albumin (Boyogen, Melbourne, Australia) in 1X Tris-buffered saline with Tween 20 (TBST; $24.7 \mathrm{mM}$ Tris- $\mathrm{HCl}, 137 \mathrm{mM} \mathrm{NaCl}$ and $0.05 \%$ Tween-20; $\mathrm{pH} 8.0$ ) and incubated overnight at $4^{\circ} \mathrm{C}$ with following primary monoclonal antibodies: Rabbit (p)mTOR, mouse (p)Akt, rabbit (p) AMPK $\alpha$ (all 1:2,000), rabbit Bax, rabbit Bak, rabbit caspase-3; and rabbit PUMA (all 1:1,000), rabbit Bcl-2 and rabbit $\beta$-actin (all 1:2,000) primary polyclonal antibodies. Membranes were washed four time with $1 \mathrm{X}$ TBST for $5 \mathrm{~min}$ at room temperature and subsequently incubated with HRP-conjugated goat anti-mouse and goat anti-rabbit polyclonal secondary antibodies (both 1:10,000) for $90 \mathrm{~min}$ at room temperature with gentle agitation. Following washing four times with $1 \mathrm{X}$ TBST for $10 \mathrm{~min}$ at room temperature, proteins were detected using SuperSignal West Pico Chemiluminescent Substrate (PI34080; Thermo Fisher Scientific, Inc., Waltham, MA, USA) and visualized on CP-BU new X-ray film (Agfa HealthCare, Inc., Mortsel, Belgium).

Caspase-3 activity assay. Cells were seeded into a six-well plate at $1 \times 10^{5}$ cells $/ \mathrm{ml}$. Following incubation for $24 \mathrm{~h}$, the cells were pre-treated with or without Compound $\mathrm{C}(10 \mu \mathrm{M})$ or LY94002 $(40 \mu \mathrm{M})$ for $30 \mathrm{~min}$ prior to treatment with CME $(160 \mu \mathrm{g} / \mathrm{ml})$. Cells were harvested using Trypsin-EDTA (Hyclone Laboratories, Inc.) and re-suspended in $50 \mu \mathrm{l}$ cold Cell Lysis Buffer on ice for $10 \mathrm{~min}$. A total of $130 \mu \mathrm{g}$ protein lysate was added to a Reaction Buffer with $10 \mathrm{mM}$ dithiothreitol. After addition of $200 \mu \mathrm{M}$ Glu-Val-Asp p-nitroanilide (DEVD-p-NA), cells were incubated at $37^{\circ} \mathrm{C}$ for $1 \mathrm{~h}$ and $30 \mathrm{~min}$. The absorbance of the solution in each well was determined using a microplate reader (Model 680; Bio-Rad Laboratories, Inc.) at $415 \mathrm{~nm}$.

Statistical analysis. LDH release and caspase-3 activity were statistically analyzed using an unpaired analysis of variance and Duncan's multiple range test using SPSS 20.0 software (IBM Corp, Armonk, NY, USA). A value of $\mathrm{P}<0.05$ was considered to indicate a statistically significant difference.

\section{Results}

CME has cytotoxic effects on HCT116 colon cancer cells. The present study investigated the cytotoxic effects of CME through the $\mathrm{LDH}$ release assay. The cells were treated with various concentrations of CME for 12 or $24 \mathrm{~h}$. As shown in Fig. 1A, LDH release significantly increased by $22.38,32.16$, $37.56,41.38$ and $50.77 \%$ following treatment with 120,140 , 160,180 or $200 \mu \mathrm{g} / \mathrm{ml} \mathrm{CME}$, respectively, compared with that in the control group $(24 \mathrm{~h} ; \mathrm{P}<0.001)$. CME significantly induced the release of LDH in a dose-dependent manner.

CME induces apoptosis in HCT116 colon cancer cells. Annexin V-PI staining and Hoechst 33342 staining were performed to identify CME-induced apoptosis. To measure the appearance of apoptotic bodies, Hoechst 33342 staining was performed. After treatment with CME (120, 140 or $160 \mu \mathrm{g} / \mathrm{ml})$ for $24 \mathrm{~h}$, the apoptotic DNA fragmentation increased in a dose-dependent manner (Fig. 1B). The cells were cultured with the CME $(120,140,160$ or $180 \mu \mathrm{g} / \mathrm{ml})$ for $24 \mathrm{~h}$ prior to Annexin V-PI staining. Then, the percentage of Annexin V-positive cells was analyzed by flow cytometry. As shown in Fig. 1C, the ratio of Annexin V-positive cells was low in the control group (14.0 6\%). However, as the concentration of CME increased, the percent of Annexin V-positive cells increased to $47.03 \%(120 \mu \mathrm{g} / \mathrm{ml})$, $52.62 \%(140 \mu \mathrm{g} / \mathrm{ml}), 53.95 \%(160 \mu \mathrm{g} / \mathrm{ml})$ and $68.01 \%(180 \mu \mathrm{g} / \mathrm{ml})$.

$C M E$ regulates the expression of mitochondria-mediated apoptotic proteins. To examine the mechanisms by which $\mathrm{CME}$ regulates signaling proteins during apoptosis, the expression of p-AMPK, p-Akt and apoptosis-associated proteins was assessed by western blot analysis. As shown in Fig. 2A, as the concentration of CME increased, the levels of p-AMPK and PUMA increased, while the levels of p-Akt, p-mTOR, pro-caspase-3 and Bcl-2 decreased. Furthermore, the mitochondria-associated apoptotic proteins Bax and Bak were increased in a dose-dependent manner (Fig. 2A).

Effect of CME on activation of caspases-3 in HCT116 colon cancer cells. Western blot analysis demonstrated that CME suppressed the expression of pro-caspase-3, indicating that pro-caspase-3 was cleaved to caspase-3 (Fig. 2A). To further determine the influence of CME on caspase- 3 activation a caspase-3 activity assay was performed using DEVD-p-NA, a substrate of caspase-3. The cells were treated with various concentrations of CME $(120,140,160$ or $180 \mu \mathrm{g} / \mathrm{ml})$ for $24 \mathrm{~h}$, followed by the measurement of the cleavage of DEVD- $p$-NA by caspase-3. The results showed that $\mathrm{CME}$ induced caspase- 3 activation through the cleavage of pro-caspase- 3 in a dose-dependent manner (Fig. 2B).

CME induces apoptosis through directly regulating the de-phosphorylation of Akt via the AMPK-independent pathway. To confirm the association between CME-induced cytotoxicity, apoptosis and the AMPK and Akt pathways, LDH release assay and Annexin V-PI staining were performed after co-treatment of the cells with Compound $\mathrm{C}$ (AMPK inhibitor) or LY294002 (Akt inhibitor) prior to incubation with CME. The results showed that the groups treated with Compound C or LY294002 only showed a similar LDH 


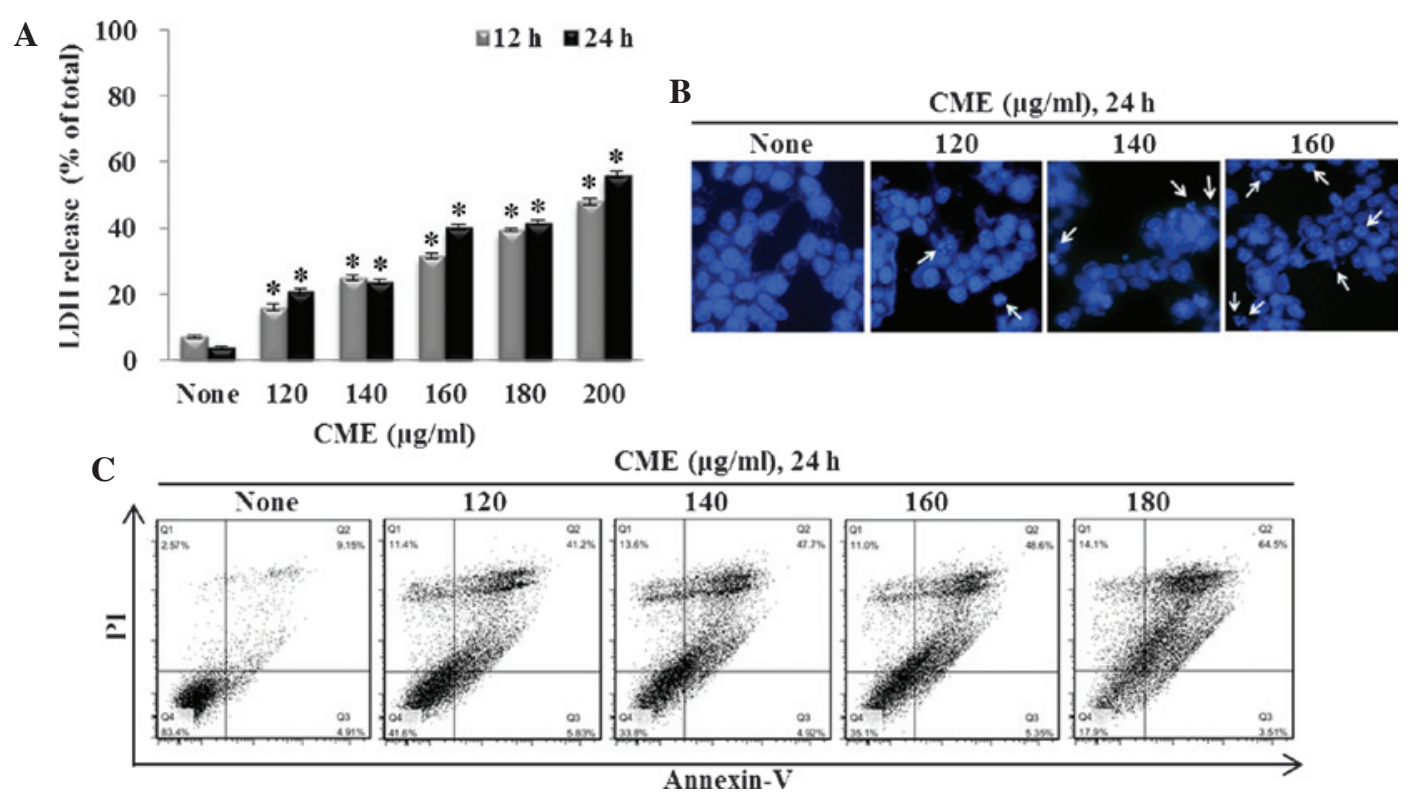

Figure 1. Cytotoxic and apoptotic effects of CME in HCT116 colon cancer cells. (A) Cells were treated with various concentrations of CME (120-200 $\mu \mathrm{g} / \mathrm{ml}$ ) for 12 or $24 \mathrm{~h}$ and subjected to an $\mathrm{LDH}$ release assay. Statistical analysis was performed using one-way analysis of variance. ${ }^{*} \mathrm{P}<0.001$ vs. the control, as determined by independent sample t-test (each experiment, $\mathrm{n}=3$ ). (B) Apoptotic bodies (white arrows) were detected by Hoechst 33342 staining (magnification, x200). (C) Apoptotic effects of CME were evaluated by Annexin V-PI staining and flow cytometric analysis. CME, Cnidium monnieri (L.) Cusson extract; $\mathrm{LDH}$, lactate dehydrogenase; PI, propidium iodide.

release to that in the control group, while treatment with CME alone or in combination with Compound $\mathrm{C}$ markedly increased the LDH release to a similar extent (Fig. 3A). Of note, the LY294002 and CME co-treated group showed a significant increase in LDH release compared with that in the CME-treated group. Apoptosis was also investigated by Annexin V/PI double staining (Fig. 3B). Treatment with Compound $\mathrm{C}$ alone decreased the apoptotic rate, while treatment with LY294002 alone increased the apoptotic rate of HCT116 cells compared with that in the control group. Treatment with CME increased the apoptotic rate, and pre-treatment with Compound $\mathrm{C}$ prior to CME treatment resulted in a similar apoptotic rate. Of note, pre-treatement with LY294002 followed by incubation with CME led to the highest apoptotic rate. All of these results indicated that CME induced apoptosis in HCT116 cells through the downregulation of Akt de-phosphorylation.

To investigate whether CME treatment decreases the dephosphorylation of Akt through the activation of AMPK or through direct inhibition, the effects of Compound C, LY294002 alone or in combination with CME on the levels of the upstream regulators (p-AMPK and p-Akt) and downstream regulators (Bcl-2, Bax, Bak and pro-caspase-3) were assessed by western blot analysis (Fig. 4A and B). When cells were treated with CME alone or pre-treated with Compound $\mathrm{C}$ followed by incubation with $\mathrm{CME}$, the expression of p-Akt, p-mTOR, pro-caspase-3 and Bcl-2 was significantly decreased $(\mathrm{P}<0.001)$, whereas $\mathrm{Bax}$ and $\mathrm{Bak}$ expression levels were significantly increased $(\mathrm{P}<0.001)$, as compared with the control group. Although the expression of p-AMPK was increased in the CME-treated group the Compound $\mathrm{C}$ and CME co-treated groups, as compared with the control, a greater increase was observed in the CME-treated group. LY294002 decreased the expression of p-mTOR, p-Akt, pro-caspase-3 and Bcl-2, and increased the expression of p-AMPK, Bax and Bak, as compared with the control. These effects were aggravated when cells were pre-treated with LY294002 and then incubated with CME.

To determine whether the CME-induced apoptosis proceeded via the mitochondrial pathway, a caspase-3 activity assay was performed (Fig. 4C). Treatment with Compound $\mathrm{C}$ alone decreased the caspase-3 activity, while treatment with LY294002 alone increased the caspase-3 activity compared with that in the control group. Caspase-3 activity was significantly increased in the CME-treated and combined treatment groups compared to those in the control group. Caspase-3 activity was not significantly different between the CME-treated group and the Compound C- or LY294002-pre-treatment + CME groups. However, the group subjected to pre-treatment with LY294002 and CME showed a slight increase in caspase-3 activation over that in the other CME-treated groups. These results indicated that CME-induced apoptosis of HCT116 colon cancer cells occurs through the de-phosphorylation of Akt and via an AMPK-independent pathway.

\section{Discussion}

Cancer is caused by the abnormal proliferation of cells, and interference with cell proliferation as well as induction of cancer cell death have been widely employed in the treatment of cancer (6). Colon cancer is of particular interest in South Korea, as its prevalence has increased with the adaptation of Western eating habits $(1,2)$. Previous studies have shown that various plant extracts have anti-cancer effects and cause apoptosis of HCT116 colon cancer cells $(4,26-28)$. The present study investigated the apoptotic effects of an extract of the fruit of Cnidium monnieri (L.) Cusson, based on previous studies $(23,25)$. Furthermore, it 

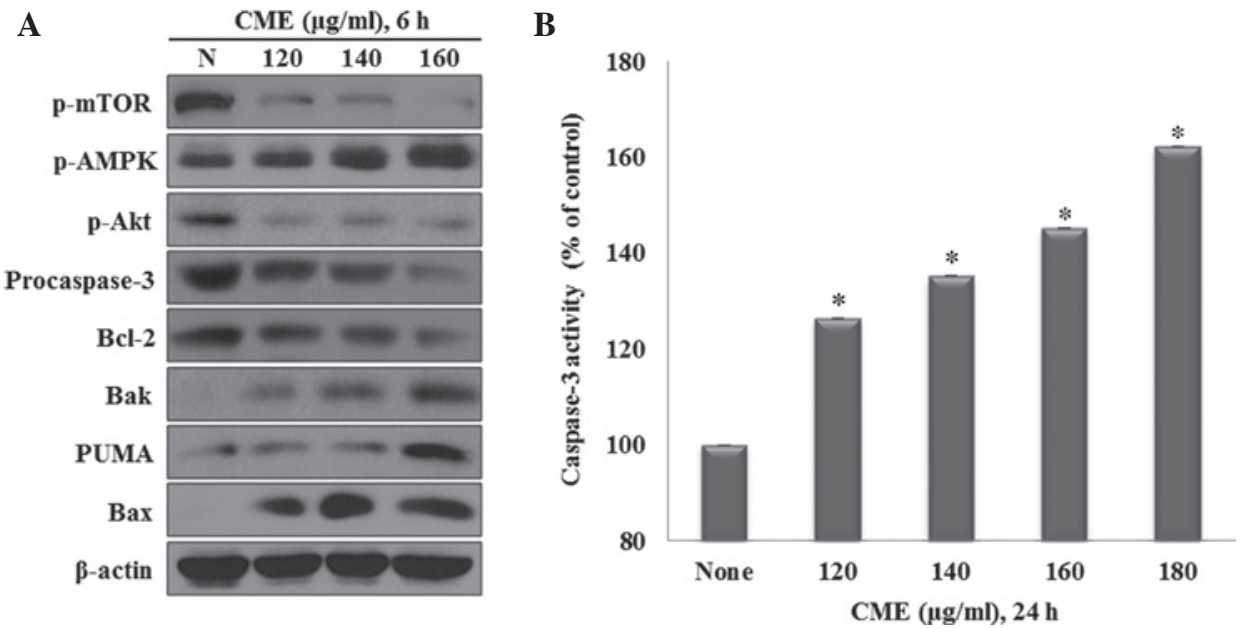

Figure 2. CME regulates the expression of mitochondria-mediated apoptotic proteins and caspase-3 activation. (A) Effects of CME on the levels of p-mTOR, p-AMPK, p-Akt, procaspase-3, Bcl-2, Bak, PUMA and Bax in HCT116 colon cancer cells. Cells were treated with 120-160 $\mu \mathrm{g} / \mathrm{ml} \mathrm{CME} \mathrm{for} 6 \mathrm{~h}$ and protein levels were determined by western blot analysis. $\beta$-actin served as a protein-loading control. (B) CME induces caspase-3 activation in HCT116 colon cancer cells. Cells were treated with CME $(120-180 \mu \mathrm{g} / \mathrm{ml})$ for $24 \mathrm{~h}$. Statistical analysis was performed using one-way analysis of variance. "P<0.001 vs. the control, as determined by independent sample $\mathrm{t}$-test (each experiment, $\mathrm{n}=3$ ). $\mathrm{p}$, phosphorylated; mTOR, mammalian target of rapamycin; AMPK, adenosine monosphosphate-activated protein kinase; PUMA, P53-upregulated modulator of apoptosis; CME, Cnidium monnieri (L.) Cusson extract; Bcl-2, B-cell lymphoma 2; Bak, Bcl-2-homologous antagonist killer; Bax; Bcl-2-associated X protein.
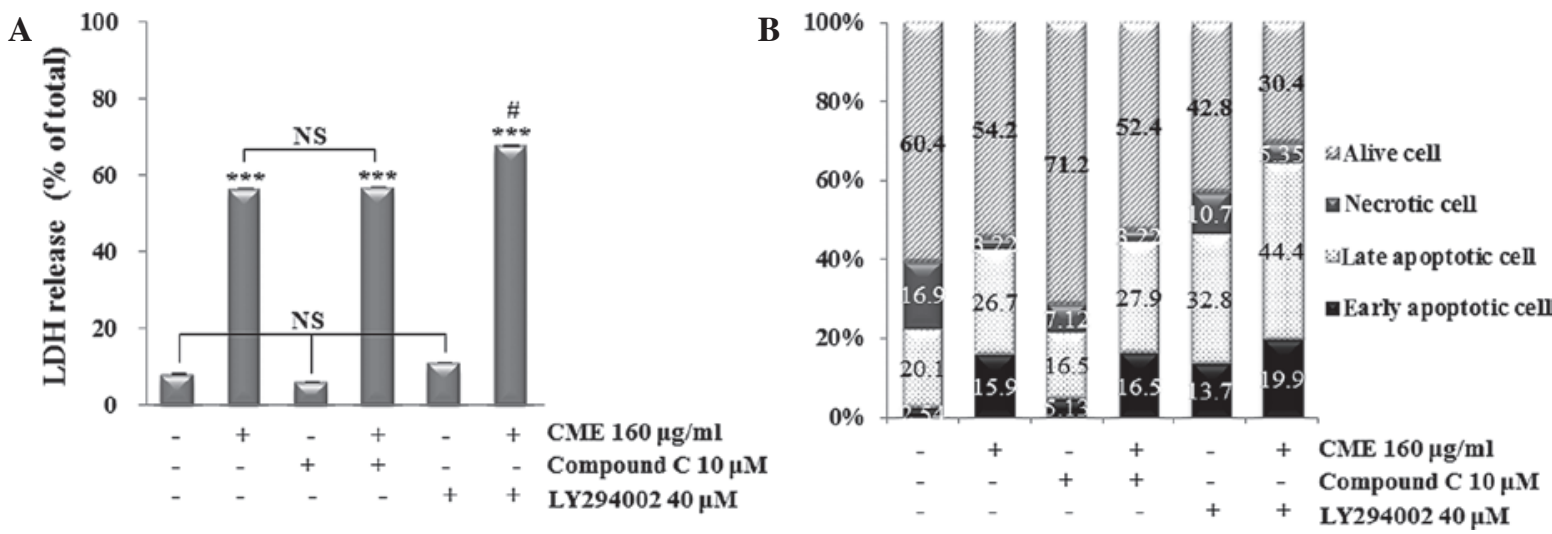

Figure 3. CMR exerts cytotoxic and apoptotic effects via the AMPK-independent pathway. Cells were pre-treated with $10 \mu \mathrm{M}$ compound C or $40 \mu \mathrm{M} \mathrm{LY} 294002$ for 30 min followed by treatment with $160 \mu \mathrm{g} / \mathrm{ml} \mathrm{CME}$ for $24 \mathrm{~h}$. (A) LDH release assay. (B) CME induced apoptosis via the AMPK-independent pathway in HCT116 colon cancer cells. Apoptosis was evaluated by Annexin V-PI staining. Statistical analysis was performed using an independent sample t-test. ${ }^{* * * *} \mathrm{P}<0.001$ vs. the control; ${ }^{*} \mathrm{P}<0.05$ vs. the $160 \mu \mathrm{g} / \mathrm{ml}$ CME-treated group (each experiment, $\mathrm{n}=3$ ).NS, not significant; CME, Cnidium monnieri (L.) Cusson extract; LDH, lactate dehydrogenase; PI, propidium iodide; AMPK, adenosine monosphosphate-activated protein kinase.

was confirmed that CME induced apoptosis through downregulating Akt, and that mitochondrial-mediated apoptotic proteins are involved via an AMPK-independent pathway.

The present study first demonstrated the cytotoxic effect of CME through the LDH release assay, as LDH release is a common marker of cellular death (29). Cellular death occurs due to various biological events, including DNA damage and metabolic stress, which also activates pro-apoptotic proteins (8). The most important pro-apoptotic proteins are Bax and Bak, which are translocated to the mitochondria upon their activation (20). Activation of Bax and Bak leads to the opening of the pore of the outer mitochondrial membrane, whichs results in apoptosis through the release of $\mathrm{LDH}$, cytochrome $\mathrm{C}$ and other molecules into the cytosol (21). For these reasons, increased levels of $\mathrm{LDH}$ release are indicative of cell death. The present study found that CME treatment increased the release of $\mathrm{LDH}$ by colon cancer cells in a dose-dependent manner.
A previous study found that curcumin treatment of HCT116 colon cancer cells augmented the number of apoptotic bodies in a dose-dependent manner (4). The present study used Annexin V/PI and Hoechst 33342 staining to quantify the occurrence of apoptosis and to observe the formation of apoptotic bodies in HCT116 cells treated with CME. The results showed that CME increased the number of Annexin V-positive, apoptotic cells and induced apoptotic DNA fragmentation.

Apoptosis signaling is regulated by molecules including AMPK and Akt in response to environmental changes $(5,8,12)$. Cancer cells regulate the activation of several signaling molecules, such as pro-survival factors, to stimulate cell growth and proliferation, and to protect themselves $(5,6)$. The induction of apoptosis through the control of pro-survival and pro-apoptotic factors been extensively studied $(1,4,6)$. Therefore, the present study investigated whether CME modulates pro-survival factors and 

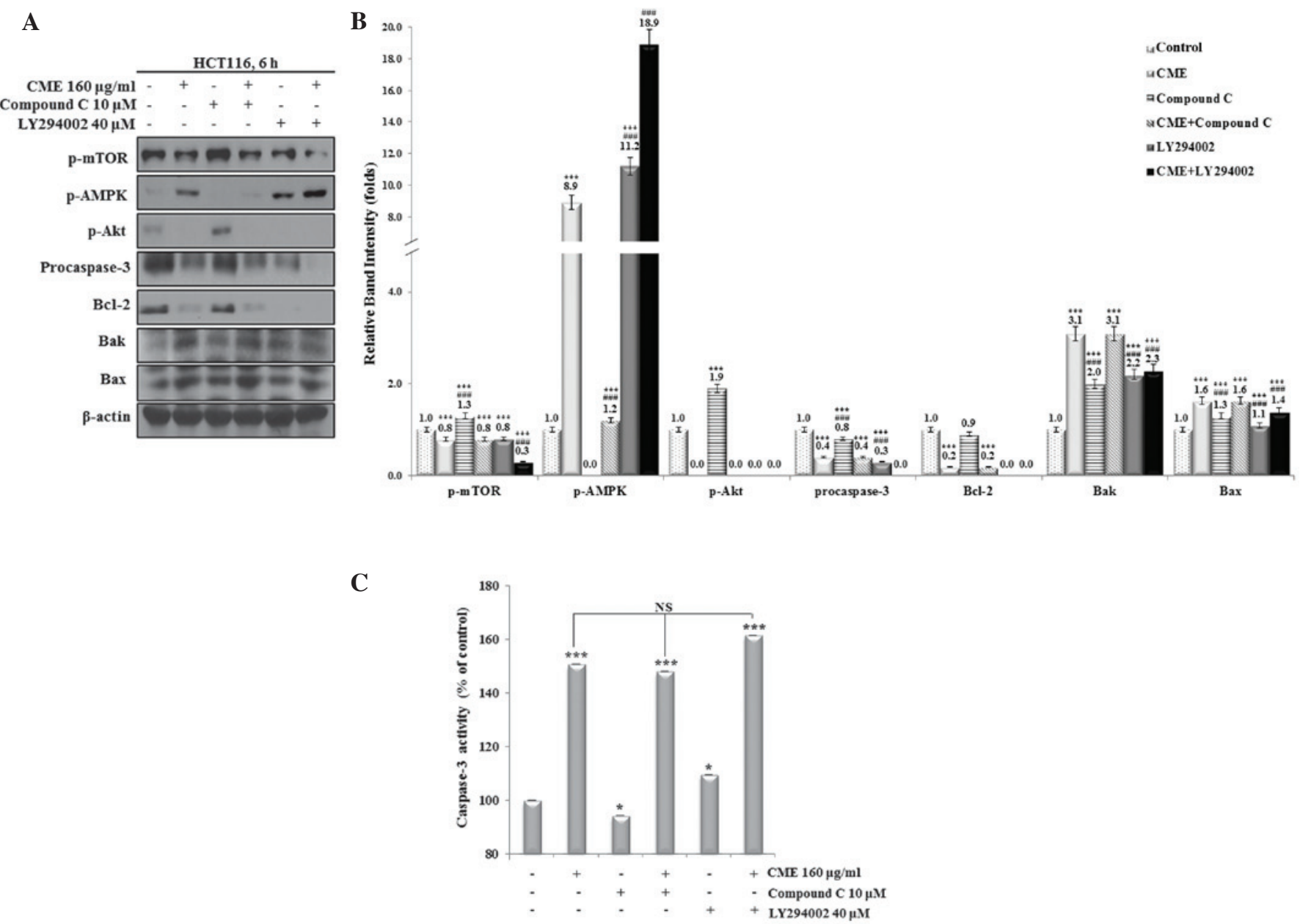

Figure 4. CME induces apoptosis through direct regulation of the dephosphorylation of Akt. (A) Pre-treatment with compound C or LY294002 prior to incubation with CME regulates p-mTOR, p-AMPK and p-Akt in HCT116 colon cancer cells. Cells were pre-treated with $10 \mu \mathrm{M}$ compound C or $40 \mu \mathrm{M}$ LY294002 for $30 \mathrm{~min}$ and then treated with $160 \mu \mathrm{g} / \mathrm{ml} \mathrm{CME}$ for $6 \mathrm{~h}$. Protein levels were determined by western blot analysis and (B) the relative band intensities were quantified. (C) Caspase-3 activity in HCT116 colon cancer cells pre-treated with compound C or LY294002 prior to incubation with CME. Caspase-3 activity was measured using a Caspase- 3 activity kit. Statistical analysis was performed using an independent sample t-test. ${ }^{*} \mathrm{P}<0.05$ and ${ }^{* * *} \mathrm{P}<0.001$ vs. the control;

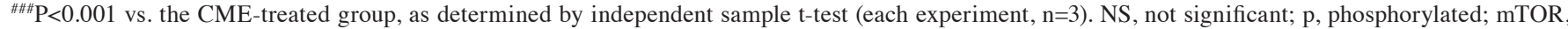
mammalian target of rapamycin; AMPK, adenosine monosphosphate-activated protein kinase; PUMA, P53-upregulated modulator of apoptosis; CME, Cnidium monnieri (L.) Cusson extract; Bcl-2, B-cell lymphoma 2; Bak, Bcl-2-homologous antagonist killer; Bax; Bcl-2-associated X protein.

pro-apoptotic mitochondrial factors through the regulation of upstream regulators, including AMPK and Akt. According to a previous study, when HT-29 colon cancer cells were treated with quercetin, the expression levels of p-AMPK, Bax, and cleaved caspase-3 were increased, while the expression of Bcl-2 was decreased (5). In addition, the activation of $\mathrm{p} 53$ by the inhibition of $\mathrm{p}$-Akt induced an increase in the expression of PUMA, which is a downstream protein of $\mathrm{p} 53$, thereby inducing apoptosis through the inhibition of Bcl-2 and cleavage of procaspase-3 $(4,30)$. Caspase- 3 is a downstream regulator of other caspases, such as caspases- 8 and 9, and can be activated by caspase-9 (15). Caspase-9, in turn, is activated through cytochrome- $\mathrm{C}$ release due to the activation of Bax and Bak $(19,22)$. When HCT116 colon cancer cells were treated with corosolic acid or Lepidium virginicum L. extract, pro-caspase-3 and Bcl-2 expression were decreased and Bax expression was increased $(27,28)$. Pro-caspase- 3 expression was also shown to be decreased by curcumin or Dorema glabrum seed extract $(26,31)$. The decline of pro-caspase-3 levels signifies an increase in cleaved, activated caspase-3 levels and apoptosis (30). The present study showed that CME treatment decreased the protein levels of p-Akt, p-mTOR, pro-caspase-3 and Bcl-2, while increasing the levels of p-AMPK, PUMA, Bax and Bak. In addition, the results clearly demonstrated that CME treatment of HCT116 colon cancer cells activated caspase-3. The present study found that CME regulated the phosphorylation of AMPK and Akt as well as the expression of apoptosis-associated proteins, including p-mTOR, PUMA, Bax and Bak.

To confirm the role of AMPK and Akt in CME-induced apoptosis, cells were pre-treated with AMPK and Akt inhibitors prior to incubation with CME. Co-treatment with CME and Compound $\mathrm{C}$ did not significantly affect the rate of $\mathrm{LDH}$ release compared to that in the CME-treated group. However, in the LY294002 + CME group, cell death was significantly increased compared with that in the CME-treated group. The LY294002-treated group also increased compared with than the control, although this difference was not significant. Furthermore, Annexin V/PI staining and flow cytometric analysis showed similar effects on the apoptotic rates. These 
results indicated that $\mathrm{CME}$ exerts cytotoxic effects and induces apoptosis via the downregulation of Akt.

p-AMPK and p-Akt are upstream regulators that trigger apoptosis through modulation of individual signaling pathways $(2,12)$. To investigate whether CME downregulates Akt through the activation of AMPK or through direct inhibition, signaling proteins associated with AMPK- and Akt-mediated apoptosis were assessed after treatment $\mathrm{CME}$ alone or following pre-treatment with AMPK and Akt inhibitors. According to the results, the expression levels of p-mTOR, p-Akt, pro-caspase-3, $\mathrm{Bcl}-2$, Bax and Bak were almost the same in the CME group and $\mathrm{CME}+\mathrm{Compound} \mathrm{C}$ group. In addition, the protein levels of p-AMPK were significantly higher in the CME group compared with those in the $\mathrm{CME}+$ Compound $\mathrm{C}$ group. The levels of the signaling proteins following treatment with LY294002 was similarly increased or decreased compared to those following treatment with $\mathrm{CME}$, and combined treatment further enhanced these effects. A previous study showed that AMPK suppresses Akt/mTOR signaling (32). However, in the present study, combined treatment with Compound $\mathrm{C}$ and CME decreased the levels of p-Akt compared to those in the groups treated with Compound $\mathrm{C}$ or CME only. Therefore, the CME-induced suppression of p-Akt was not caused by an increase of $\mathrm{p}$-AMPK, but by the direct suppression of the dephosphorylation of Akt. p-Akt suppresses the translocation of Bax to the mitochondria, while LY294002 increases Bax translocation (21). The present study showed that Bax and Bak expression following various treatments was increased compared to that in the control. LY294002 treatment led to similar increases in Bax to those following CME treatment, and the trend was further amplified following combined treatment of LY294002 and CME. Activation of Bax and Bak induces caspase-3 activity (5). Therefore, the present study performed a caspase-3 activity assay to determine whether CME-induced apoptosis proceeded via the mitochondrial pathway. There were no significant differences in caspase-3 activity between the group co-treated with Compound $\mathrm{C}$ and $\mathrm{CME}$ and that treated with $\mathrm{CME}$ alone. This also supported the finding that $\mathrm{CME}$ induced apoptosis through an AMPK-independent pathway. A previous study has shown that LY294002 treatment is capable of increasing caspase-3 activation in human umbilical vein endothelial cells (33). In the present study, LY294002 treatment of HCT116 colon cancer cells also significantly increased caspase- 3 activity compared to that in the control group. In addition, in the LY294002 + CME group, caspase activation was slightly, but not significantly increased compared to that in the CME-treated group.

The present study was the first to report that $\mathrm{CME}$ induced apoptosis by exerting metabolic stress through direct regulation of p-Akt via an AMPK-independent pathway in HCT116 colon cancer cells. CME directly downregulated Akt, which suppressed Bcl-2, activated Bax and Bak, and led to apoptosis by caspase- 3 activation and possibly through cytochrome $\mathrm{C}$ release.

\section{Acknowledgements}

The present study was supported by the Korea Research Foundation Grant (grant no. KRF-2010-0021402) and the Technological Innovation R\&D Program (grant no. S2128176) funded by the Small and Medium Business Administration (SMBA, Korea).

\section{References}

1. Park SY, Kim IS, Lee SH, Lee SH, Jung DW, Park OJ and Kim YM: Anti-proliferative effects of selenium in HT-29 colon cancer cells via inhibition of Akt. J Life Sci 22: 55-61, 2012.

2. Lee SH, Park SY, Kim IS, Park OJ and Kim YM: Effects of resveratrol on migration and proliferation in HT-29 colon cancer cells. KSBB J 27: 289-294, 2012.

3. Grady WM and Markowitz SD: Genetic and epigenetic alterations in colon cancer. Annu Rev Genomics Hum Genet 3: 101-128, 2002

4. Park SY, Lee SH, Park OJ and Kim YM: Apoptotic effects of curcumin and EGCG via Akt-p53 signaling pathway in HCT116 colon cancer cells. J Life Sci 21: 89-95, 2011.

5. Lee SH, Jung DW, Kim GT, Park SY, Kim SY, Park OJ and Kim YM: Quercetin of plants extracts regulates sestrin2 and induces apoptosis in HT-29 colon cancer cells. Cancer Prev Res 17: 244-250, 2012.

6. Lee SH, Kim GT, Kim JI, Lim EG, Kim IS and Kim YM: The Extract from Lysimachia foenum-graecum induces apoptosis in MCF-7 breast cancer cells. KSBB J 28: 303-309, 2013.

7. Lee YK, Park SY, Kim YM, Kim DC, Lee WS, Surh YJ and Park OJ: Suppression of mTOR via Akt-dependent and -independent mechanisms in selenium-treated colon cancer cells: Involvement of AMPKalpha1. Carcinogenesis 31: 1092-1099, 2010.

8. Park C, Jin CY, Choi TH, Hong SH and Choi YH: Effect on proapoptotic $\mathrm{Bcl}-2$ on naringenin-induced apoptosis in human leukemia U937 cells. J Life Sci 23: 1118-1125, 2013.

9. Park SY, Lee SH, Park OJ and Kim YM: Apoptotic effects of selenium via AMPK-VASP signal pathway in B16F10 melanoma cells. Cancer Prev Res 15: 313-319, 2010.

10. Seo BR, Min KJ, Cho IJ, Kim SC and Kwon TK: Curcumin significantly enhances dual PI3K/Akt and mTOR inhibitor NVP-BEZ235-induced apoptosis in human renal carcinoma caki cells through down-regulation of p53-dependent Bcl-2 expression and inhibition of Mcl-1 protein stability. PLoS One 9: e9558, 2014

11. Greer EL, Oskoui PR, Banko MR, Maniar JM, Gygi MP, Gygi SP and Brunet A: The energy sensor AMP-activated protein kinase directly regulates the mammalian $\mathrm{FOXO} 3$ transcription factor. J Biol Chem 282: 30107-30119, 2007.

12. Kim D and Chung J: Akt: Versatile mediator of cell survival and beyond. J Biochem Mol Biol 35: 106-115, 2002.

13. Cory S, Huang DC and Adams JM: The Bcl-2 family: Roles in cell survival and oncogenesis. Oncogene 22: 8590-8607, 2003.

14. Lavi I, Friesem D, Geresh S, Hadar Y and Schwartz B: An aqueous polysaccharide extract from the edible mushroom Pleurotus ostreatus induces anti-proliferative and pro-apoptotic effects on HT-29 colon cancer cells. Cancer Lett: 61-70, 2006.

15. Deng YB, Lin YH and Wu XW: TRAIL-induced apoptosis requires Bax-dependent mitochondrial release of Smac/DIABLO. Genes Dev 16: 33-45, 2002.

16. Jiang M, Wang CY,Huang S, Yang T and Dong Z: Cisplatin-induced apoptosis in p53-deficient renal cells via the intrinsic mitochondrial pathway. Am J Physiol Renal Physiol 296: F983-F993, 2009.

17. Zhuang S, Yan Y, Daubert RA, Han J and Schnellmann RG: ERK promotes hydrogen peroxide-induced apoptosis through caspase-3 activation and inhibition of Akt in renal epithelial cells. Am J Physiol Renal Physiol 292: F440-F447, 2007.

18. Jeong SY and Seol DW: The role of mitochondria in apoptosis. BMB Rep 41: 11-22, 2008.

19. Chien SY, Wu YC, Chung JG, Yang JS, Lu HF, Tsou MF, Wood WG, Kuo SJ and Chen DR: Quercetin-induced apoptosis acts through mitochondrial- and caspase-3-dependent pathways in human breast cancer MDA-MB-231 cells. Hum Exp Toxicol 28: 493-503, 2009.

20. Degli Esposti M and Dive C: Mitochondrial membrane permeabilisation by Bax/Bak. Biochem Biophys Res Commun 304: 455-461, 2003.

21. Tsuruta F, Masuyama N and Gotoh Y: The phosphatidylinositol 3-kinase (PI3K)-Akt pathway suppresses bax translocation to mitochondria. J Biol Chem 277: 14040-14047, 2002.

22. Twiddy D and Cain K: Caspase-9 cleavage, do you need it? Biochem J 405: e1-2, 2007. 
23. Yang LL, Wang MC, Chen LG and Wang CC: Cytotoxic activity of coumarins from the fruits of Cnidium monnieri on leukemia cell lines. Planta Med 69: 1091-1095, 2003.

24. Zhu YP: Tonifying herbs In: Chinese Material Medica: Chemistry, Pharmacology And Applications. Harwood Academic Publishers, Amsterdam, pp624, 1998.

25. Chou SY, Hsu CS, Wang KT, Wang MC and Wang CC: Antitumor effects of osthol from Cnidium monnieri: An in vitro and in vivo study. Phytother Res 21: 226-230, 2007.

26. Watson JL, Hill R, Lee PW, Giacomantonio CA and Hoskin DW: Curcumin induces apoptosis in HCT-116 human colon cancer cells in a p21-independent manner. Exp Mol Pathol 84: 230-233, 2008.

27. Sung B, Kang YJ, Kim DH, Hwang SY, Lee YJ, Kim MJ, Yoon JH, Kim CM, Chung HY and Kim ND: Corosolic acid induces apoptotic cell death in HCT116 human colon cancer cells through a caspase-dependent pathway. Int J Mol Med 33: 943-949, 2014.

28. Chae YH, Shin DY, Park C, Lee YT, Moon SG and Choi YH: Induction of apoptosis in human colon carcinoma HCT116 cells using a water extract of Lepidium virginicum L. J Korean Soc Food Sci Nutr 40: 649-659, 2011.
29. Moran JH and Schnellmann RG: A rapid beta-NADH-linked fluorescence assay for lactate dehydrogenase in cellular death. J Pharmacol Toxicol Methods 36: 41-44, 1996.

30. Lee WK and Kim SJ: Sulforaphane-induced apoptosis was regulated by $\mathrm{p} 53$ and Caspase- 3 dependent pathway in human chondrosarcoma, HTB-94. J Life Sci 21: 851-857, 2011.

31. Bannazadeh Amirkhiz M, Rashtchizadeh N, Nazemiyeh $H$, Abdolalizadeh J, Mohammadnejad L and Baradaran B: Investigating apoptotic effects of methanolic extract of Dorema glabrum seed on WEHI-164 cells. ISR N Pharmacol 2013: 949871, 2013.

32. Pantovic A, Krsti A, Janjetovica K, Kocic J, Harhaji-Trajkovic L, Bugarski D and Trajkovi V: Coordinated time-dependent modulation of AMPK/Akt/mTOR signaling and autophagy controls osteogenic differentiation of human mesenchymal stem cells. Bone 52: 524-531, 2013.

33. Shi $\mathrm{H}$ and Feng JM: Aristolochic acid induces apoptosis of human umbilical vein endothelial cells in vitro by suppressing PI3K/Akt signaling pathway. Acta Pharmacologica Sinica 32: 1025-1030, 2011 